\title{
特集 治療困難な動脈瘤の手術
}

\section{原 著}

\section{クリッピング困難な内頝動脈瘤に対するバイパス併用手術}

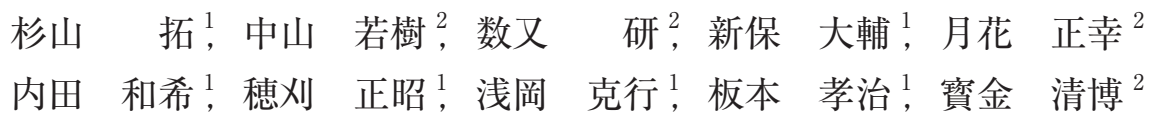

\section{The Role of Bypass Procedure in the Surgical Treatment of Complex Internal Carotid Artery Aneurysms}

Taku SugiYama, M.D. ${ }^{1}$, Naoki Nakayama, M.D. ${ }^{2}$, Ken Kazumata, M.D. ${ }^{2}$, Daisuke Shimbo, M.D. ${ }^{1}$, Masayuki GEKKA, M.D. ${ }^{2}$, Kazuki UCHIDA, M.D. ${ }^{1}$, Masaaki HoKARI, M.D. ${ }^{1}$, Katsuyuki Asaoka, M.D. ${ }^{1}$, Kouji IтAmoto, M.D. ${ }^{1}$, and Kiyohiro Houkin, M.D. ${ }^{2}$

${ }^{1}$ Department of Neurosurgery, Teine Keijinkai Hospital, and ${ }^{2}$ Department of Neurosurgery, Hokkaido University Graduate School of Medicine, Sapporo, Hokkaido, Japan

Summary: The treatment of complex internal carotid artery (ICA) aneurysms is still a controversial issue. This study aimed to evaluate the safety and efficacy of a surgical strategy using the bypass procedure in such patients. We retrospectively reviewed the clinical and radiological records of 50 consecutive patients with 52 complex ICA aneurysms who underwent bypass surgery. In this study, we divided the ICA into 3 segments based on the origin of the ophthalmic artery (OpthA) and posterior communicating artery (PComA). All patients with an aneurysm located in the portion proximal to the OpthA (segment 1) were treated with bypass and proximal ICA occlusion, and only 1 patient (5.2\%) experienced an ischemic complication. Among patients with an aneurysm located between the OpthA and PComA (segment 2), 14 were treated with bypass and trapping, and 10 were treated with clipping under bypass. Among these, 3 (12.5\%) had an ischemic complication and 1 (4.2\%) had a hemorrhagic complication. Among patients with an aneurysm located distal to the PComA (segment 3), clipping under temporary bypass was performed in 2 , clipping with bypass and proximal occlusion in 4 , trapping in 2, and bypass and proximal occlusion in 1. However, 4 of 9 (44.4\%) patients had an ischemic complication. Finally, 41 of 50 (82.0\%) patients showed a favorable outcome (modified Rankin scale $0-2$ ) in this series. In conclusion, the results of our surgical strategy using a bypass procedure were acceptable; however, ischemic complications were a persistent problem in aneurysms located distal to the PComA.

はじめに

大型/巨大脳動脈瘤, 解離/血豆状脳動脈瘤, 治療後再発 の動脈瘤などは, 時に通常の脳動脈瘤頝部クリッピングや 瘤内コイル塞栓術では治療が困難である ${ }^{47)}$ 。これらに対

\author{
Key words: \\ - complex aneurysm \\ - complication \\ - extracranial-intracranial \\ bypass \\ - high-flow bypass \\ • internal carotid artery
}

Surg Cereb Stroke

(Jpn) 44: 183-188, 2016

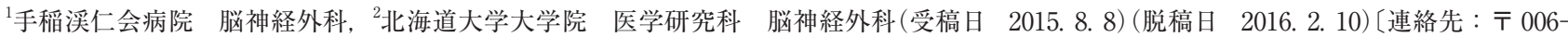
8555 北海道札幌市手稲区前田 1 条 12丁目 1-40 手稲溪仁会病院 脳神経外科 杉山 拓] [Address correspondence: Taku SugIYAMA, M.D., Ph.D., Department of Neurosurgery, Teine Keijinkai Hospital, Maeda 1-12, Teine-ku, Sapporo, Hokkaido 006-8555, Japan] 
る。また, flow diverter と総称されるステント治療が新 たに脚光を浴びつつある現在 ${ }^{91113)}$ ，どういった症例に対 してバイパス手術が有効であるかを検討する必要性がある.

ICA は, 前大脳動脈 (anterior cerebral artery：ACA) と 中大脳動脈 (middle cerebral artery：MCA)の血流を担い, さらには, 後交通動脈 (posterior communicating artery : PComA) やその穿通枝, 前脈絡叢動脈 (anterior choroidal artery：AChA), 眼動脈 (ophthalmic artery：OpthA) な どの重要血管が分枝するという特徵を有する。何らかの母 血管閉塞を伴うバイパス併用手術においては，脳動脈瘤の 大きさや形状以上に，これら重要血管との位置関係が手術 成功に影響すると考えられる(10).

本研究では, 血管分枝に応じて内頚動脈を 3 つに分類 し，それぞれにおける手術戦略を整理した。また，治療成

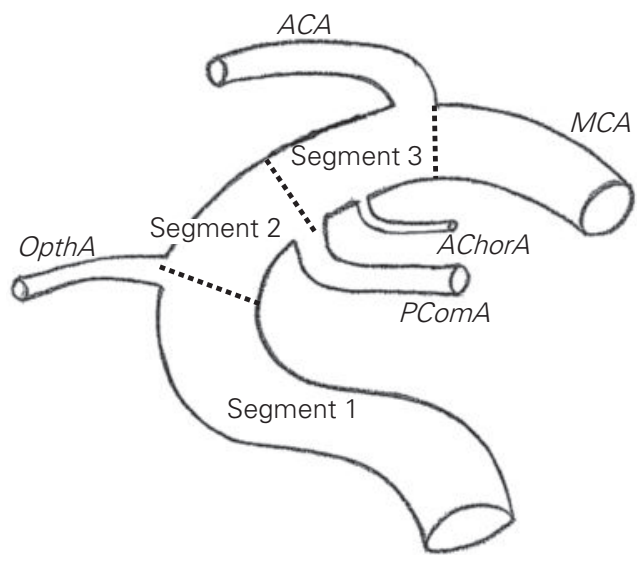

Fig. 1 The internal carotid artery (ICA) is divided into 3 segments based on the origin of the ophthalmic artery (OpthA) and posterior communicating artery (PComA).
績，合併症を検討することで，手術の問題点を考察したの で報告する。

\section{対象と方法}

\section{1. 血管分岐位置による内頚動脈瘤の分類}

動脈瘤を血管分岐の観点から，以下のごとく分類した

(Fig. 1).

(1) Segment 1：ICA 起始部から OpthA 分岐部

(2) Segment 2: OpthA 分岐部から PComA 分岐部

(3) Segment 3:PComA 分岐部から終末部

なお，ICA-OpthA 分岐部動脈瘤は Segment 2, ICAPComA 分岐部動脈瘤および ICA 先端部動脈瘤は Segment 3 に含めた.

\section{2. 手術戦略}

ICA 領域，すなわち ACA および MCA 領域の両者の再 建は, high flow bypass (HFB)を原則とし, われわれは, 閉塞試験を通常は実施していない. HFBの手技の詳細 は，他の文献を参照されたい(12)5).

以下に, バイパス血流の流出経路の視点から, 各 segment ごとの手術コンセプトを提示する.

\section{(1) Segment 1}

バイパスおよび近位部(頝部)内頝動脈の結紮を実施す る。すなわち，バイパスの血流，あるいは PComA や AComA 介した血流は, ICAを逆行性に流れ, OpthA に流出する形となる(Fig. 2)

\section{(2) Segment 2}

バイパス下の trappingを基本とする。原則的には, OpthAの遠位と, PComAの近位で trappingする(Fig. 3).すなわち, ICA の順行性血流は OpthA に流出する形 となり, バイパスの血流は, PComA に流出される形とな
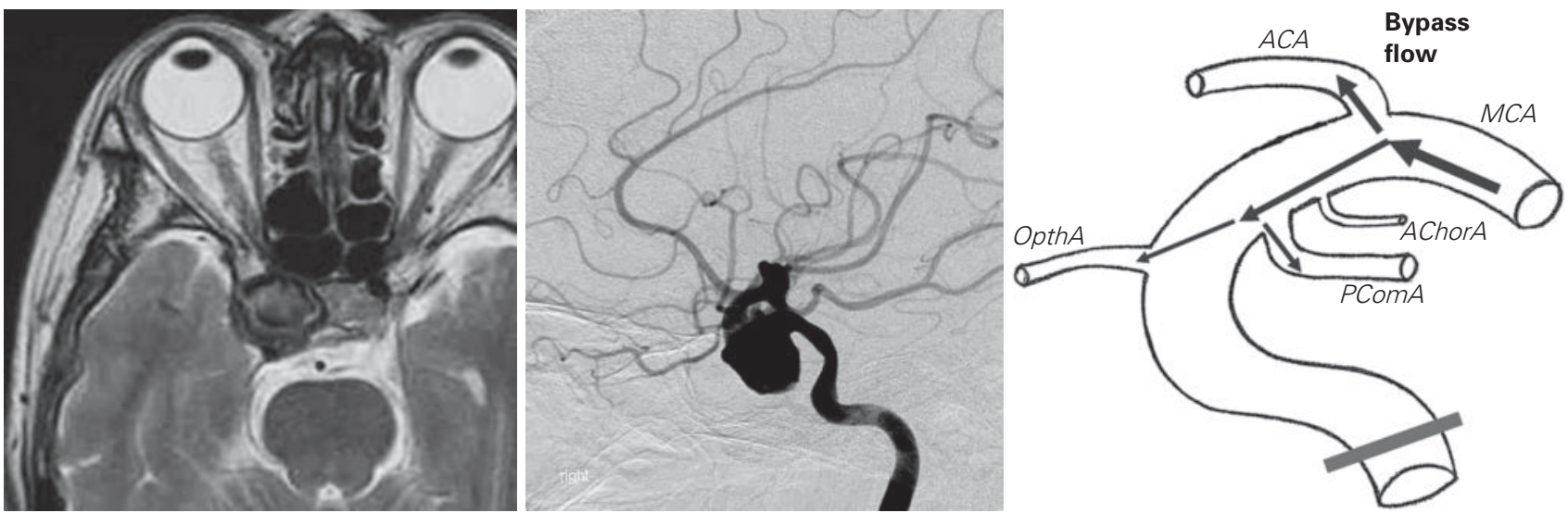

A $|\mathbf{B}| \mathbf{C}$

Fig. 2 Representative case of large aneurysm in segment 1 (A, B). The drawing shows the surgical strategy using bypass and proximal ICA occlusion (C). 

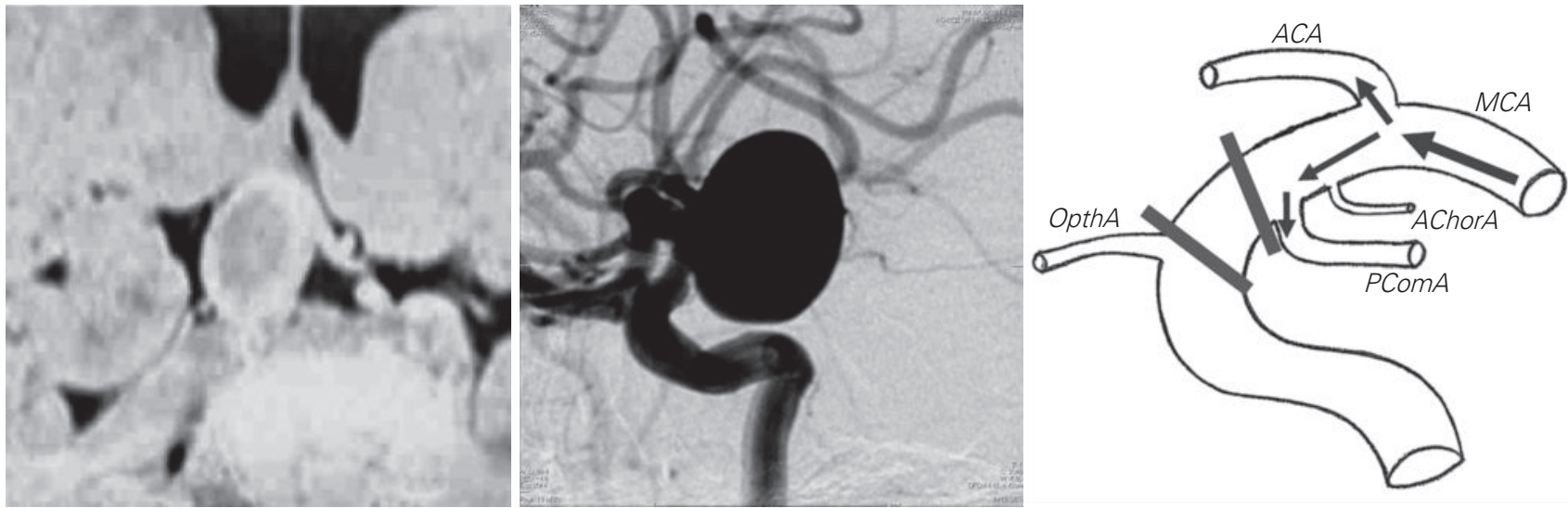

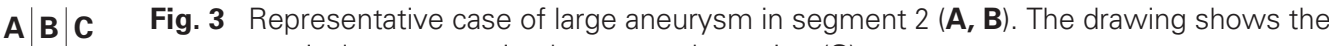
surgical strategy using bypass and trapping (C).
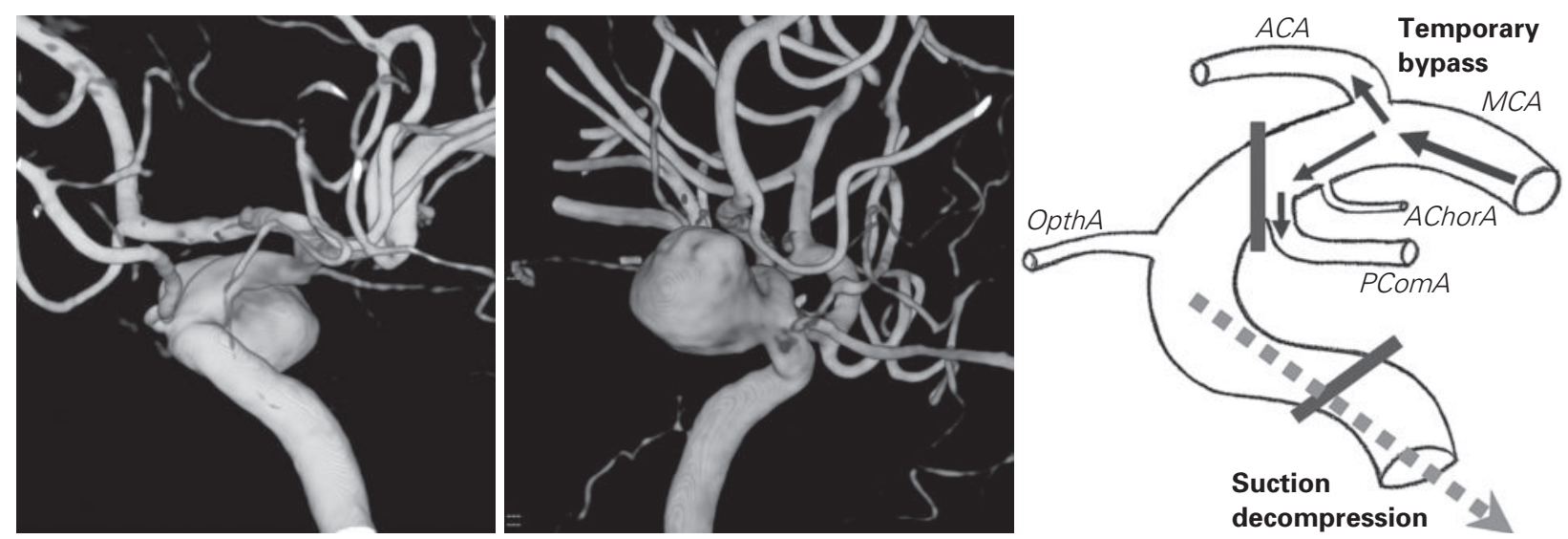

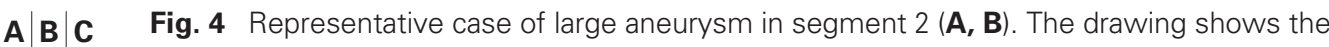
surgical strategy using bypass and trapping (C).

る．また，結果的に clipping が可能であるが，剥離に時 間を要すると考えられる症例などでは, 腕挙げ法などの temporary use のバイパスのもと, 全遮断や suction decompression 法などを用いてこれを行う(Fig. 4).

(3) Segment 3

AChoA などの穿通枝の温存が焦点になる. バイパスお よび近位部内頝動脈閉塞を実施することにより，動脈瘤へ の血流を逆向性に変化させるとともに血流量を減じ, その うえで clipping に挑戦する手法が一法である(Fig. 5D). また, trapping を行う場合でも, clip blade を ICA に対し て斜めに挿入することにより， PComA の温存を試みるの が一法である(Fig. 5E).

\section{対象と治療成績}

2002 年 4 月から 2014 年 4 月までにわれわれの施設で, バイパス併用手術を実施した 50 症例 52 内頚動脈瘤を対象
とし，後方視的に治療成績と手術合併症を調查した，年齢 は $55.3 \pm 15.4$ 歳，男性 10 人，女性 40 人であった，動脈瘤 の性質としては, 大型/巨大/血检化が 35 例, 解離/血豆状 が 15 例，治療後再発が 2 例であった。部位別には，Segment 1 が 19 例, Segment 2 が 24 例, Segment 3 が 9 例 であった．破裂症例は 22 例(そのうち, World Federation of Neurological Surgeons〔WFNS] grade 1-3 の軽症例は 9 例，4-5 の重症例は 13 例)，未破裂が 30 例 (そのうち, 10 例が症候性)であった。

治療成績には, modified Rankin Scale (mRS)を用い, mRS 0-2 を転帰良好とした。術後合併症は，明らかな神 経症状の変化を伴う症例でかつ画像上術後に新たに確認さ れた虚血性合併症，虚血性眼症を含めた。さらに，再出血 event，その他の神経症状の悪化を伴う合併症を調べた. 破裂症例に抒いては, 脳血管攣縮による虚血性合併症と区 別するため，虚血性合併症の画像評価は，発症後 1-3 日目 

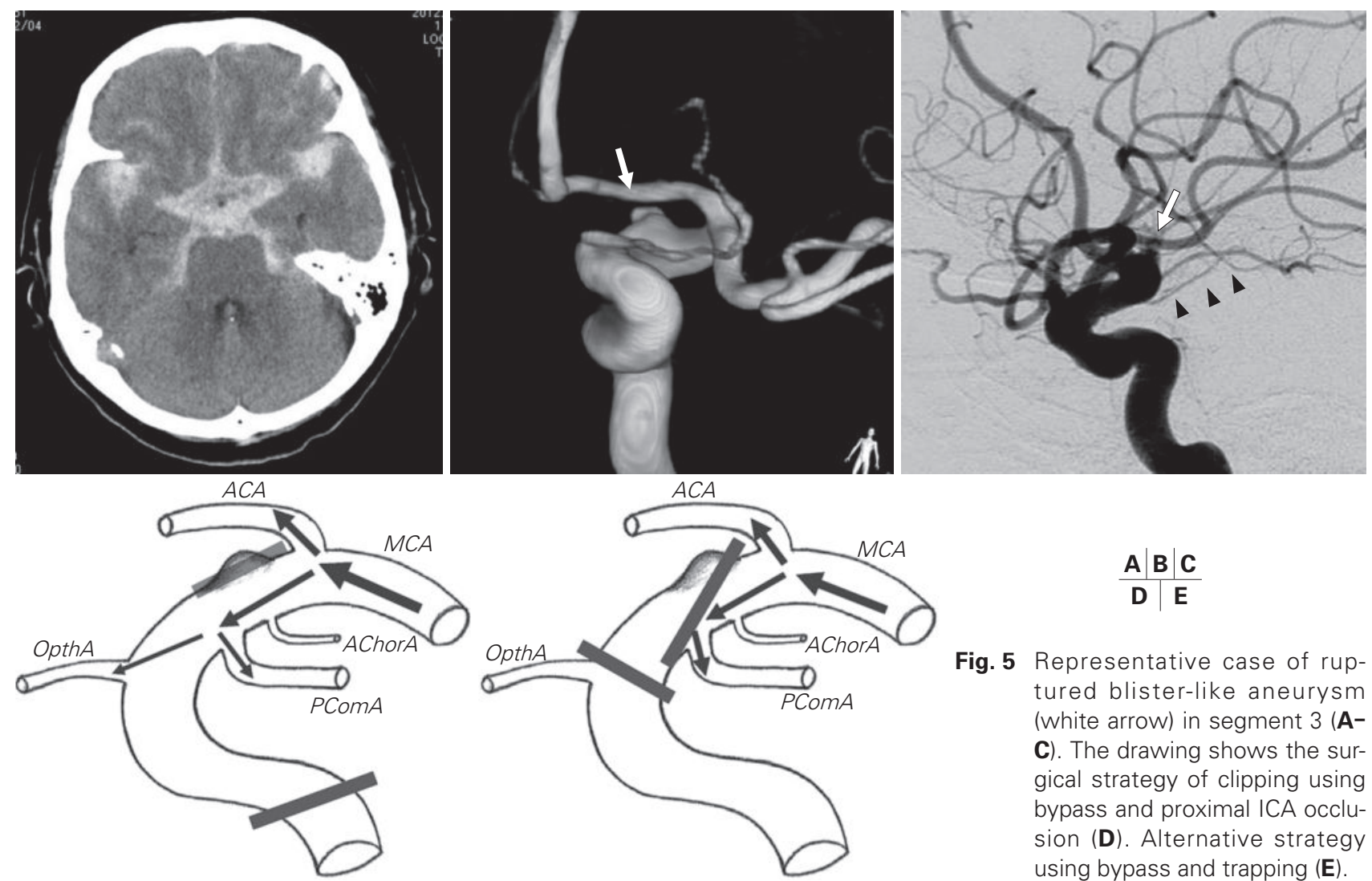

Fig. 5 Representative case of ruptured blister-like aneurysm (white arrow) in segment 3 (AC). The drawing shows the surgical strategy of clipping using bypass and proximal ICA occlusion (D). Alternative strategy using bypass and trapping (E).

までのものを用いた．全例が発症 2 日以内に手術されてい た。

\section{手術合併症に関係する因子}

手術合併症に関係する因子は，ロジスティック回帰分析 にて検討した，多変量解析に先立ち，患者側の要因(年 齢, 性別), 動脈瘤による要因(破裂/未破裂, 性状, 部 位), 手術法による要因(バイパスの種類, 動脈瘤治療の種 類）の各因子と, 術後合併症の有無との関係の単変量解析 をそれぞれ行った，単変量解析にて $\mathrm{p}<0.10$ となる因子に て多変量解析を実施した， p < 0.05 を有意水準とした。統 計解析ソフトは Excel 統計 Ver. 6.05(エスミ, 東京)を使 用した。

\section{結果}

結果のまとめを Table 1 に示す.

バイパスの種類としては, ACA への血流が対側から十 分に賄われていた 2 例，軟部組織の腫瘍で graft の通過が 困難であった 1 例で，また，ICA 先端部の血栓化動脈瘤 の 1 例では血流量の減少を意図して, low flow bypass （LFB）を選択した。結果, 浅側頭動脈 (superficial temporal artery：STA)-MCA bypass 4 例, 外頚動脈 (external carotid artery：ECA)-橈骨動脈 (radial artery：RA)-MCA bypass 40 例, temporary RA bypass(腕挙げ法) 8 例で あった，動脈瘤治療法としては, Segment 1 では全例が近 位部閉塞を実施，Segment 2 では，14 例で trapping, 8 例で temporary bypass のもとでの clipping, 2 例で近位 部閉塞下の clipping を実施した. Segment 3 では, 5 例で 近位部閉塞下 clipping, 2 例 で trapping, 1 例で temporary bypass のもとでの clipping, 1 例では LFB 下の近位 部閉塞を実施した，術後の全成績としては，50 例中 41 例 で良好な転帰が得られた。

術後の出血性合併症は，1例にのみ認めた. Segment 2 の血豆状動脈瘤に対して, 腕挙げ法のもと clipping を実 施した症例で, 術直後に再出血が認められた。 その他, Segment 3 の症例で感染性合併症を 1 例に認めた.

虚血性合併症は，8例に認められた。1例は，OpthAを も trapping に含めた Segment 2 の大型動脈瘤で, 術後に 虚血性の視神経障害を呈した。LFB を選択した 4 例のう ち 2 例では, 血行力学的な梗塞と考えられる分水界領域の 皮質梗塞が認められた。 また, 塞栓性の梗塞と考えられる 皮質梗塞が HFB の 2 例に認められた。穿通枝領域の梗塞 は 3 例に認め, そのうち 1 例は Segment 2 のものであっ た。この症例は, 穿通枝は trapping に含まれていなかっ 
Table 1 Summary of clinical characteristics, surgical procedures and, outcomes in this series

\begin{tabular}{lccc}
\hline & Segment 1 & Segment 2 & Segment 3 \\
\hline $\mathrm{n}$ & 19 & 24 & 9 \\
Patient Characteristics & & & \\
Age & $56.8 \pm 16.0$ & $49.5 \pm 12.9$ & $67.2 \pm 13.5$ \\
Sex (Male/Female) & $2 / 15$ & $4 / 20$ & $4 / 5$ \\
Unruptured & 19 & 10 & 1 \\
Ruptured (poor grade) & 0 & $14(8)$ & $8(5)$ \\
Aneurysm Characteristics & 19 & 14 & 2 \\
$\quad$ Giant-large & 0 & 10 & 5 \\
Blister-like & 0 & 0 & 2 \\
Previously treated & 1 & 1 & 2 \\
Bypass & 18 & 16 & 6 \\
STA-MCA bypass & 0 & 7 & 1 \\
ECA-RA-MCA & 19 & 0 & 1 \\
Temporary RA bypass & 0 & 14 & 2 \\
Treatment & 0 & 8 & 1 \\
PO & 0 & 2 & 5 \\
Trapping & & & \\
Clipping & $1(5.2 \%)$ & $3(12.5 \%)$ & $4(44.4 \%)$ \\
PO \& clipping & 0 & $1(4.2 \%)$ & 0 \\
Complication & 0 & 0 & $1(11.1 \%)$ \\
Ischemic (\%) & & & \\
Hemorrhagic (\%) & $19(79.2 \%)$ & $4(44.4 \%)$ \\
Other (\%) & $(100 \%)$ & $19(\%)$ \\
Outcome & mRS 0-2 (\%) &
\end{tabular}

ECA: external carotid artery, MCA: middle cerebral artery, mRS: modified Rankin Scale, PO: proximal occlusion, RA: radial artery, STA: superficial temporal artery

Table 2 Univariate analysis for detecting the predictors of surgical complications

\begin{tabular}{|c|c|c|c|c|}
\hline & \multirow{2}{*}{$\begin{array}{l}\text { Complication } \\
(-)\end{array}$} & \multirow{2}{*}{$\begin{array}{l}\text { Complication } \\
\qquad(+)\end{array}$} & \multicolumn{2}{|c|}{ Univariate analysis } \\
\hline & & & OR $(95 \% \mathrm{Cl})$ & $\mathrm{p}$ \\
\hline $\mathrm{n}$ & 42 & 10 & & \\
\hline \multicolumn{5}{|l|}{ Characteristics of PT } \\
\hline Age & $54.4 \pm 15.8$ & $57.2 \pm 14.8$ & $1.00(0.96-1.05)$ & 0.838 \\
\hline$M ; F$ & $5 ; 37$ & $4 ; 6$ & $4.93(1.02-23.8)$ & $0.047^{*}$ \\
\hline \multicolumn{5}{|l|}{ Characteristics of AN } \\
\hline Ruptured; Unruptured & $15 ; 27$ & $7 ; 3$ & $4.20(0.94-18.7)$ & 0.059 \\
\hline Giant-large; Blister-like; Previously treated & $30 ; 11 ; 1$ & $5 ; 4 ; 1$ & $2.31(0.74-7.28)$ & 0.151 \\
\hline Location (segment $1 ; 2 ; 3$ ) & $18 ; 20 ; 4$ & $1 ; 4 ; 5$ & $5.10(1.54-16.9)$ & $0.008 * *$ \\
\hline \multicolumn{5}{|l|}{ Surgical procedure } \\
\hline Bypass (HFB; LFB) & $40 ; 2$ & $8 ; 2$ & $5.00(0.61-40.9)$ & 0.133 \\
\hline PO; Trapping; Clipping; PO + Clipping & $18 ; 12 ; 7 ; 5$ & $2 ; 4 ; 2 ; 2$ & $1.45(0.76-2.76)$ & 0.256 \\
\hline
\end{tabular}

PT: patients, AN: aneurysm, HFB: high flow bypass, LFB: low flow bypass, OR: odds ratio, PO: proximal occlusion, ${ }^{*} p<0.05, * * p<0.01$

たが, PComA が adult type であった. その他の 2 例の穿 通枝梗塞は, いずれも Segment 3 の血豆状動脈瘤の症例 であった。

合併症率を部位別に示すと, Segment 1 で $5.2 \%$, Segment 2 で $16.7 \%$, Segment 3 で $55.6 \%$ と, Segment 3 で
合併症が多く認められた，単変量解析では，術後の合併症 に関係する因子として，“性別”と“動脈瘤の部位”が有 意であり, 特に後者は強い相関が示唆されたものの (Table 2)，多変量解析では，いずれの因子も有意と判定されな かった。 


\section{考察}

本研究の結果, 複雑な内䅡動脈瘤に対する治療法とし て，バイパス併用手術の結果は全体としては良好であっ た。しかしながら，治療成績は瘤の部位に応じて異な り，特に Segment 3，すなわち PComA よりも遠位部の動 脈瘤では，治療成績に課題が残ることが浮き彫りになった。

今回，われわれの提示した手術コンセプトは，基本的に “穿通枝を盲端化しない”という思想背景のもとに構築さ れている。穿通枝は，単に開存していればよいのではな く，血流の終点が穿通枝で終わってしまう形にした場合 (盲端化)，血栓化が生じてしまう可能性が指摘されている ためである(7)1212. そのため, バイパス血流の流出路を OpthA や PComA に求めることから方法論を構築してい る.

事実上の結果からも，Segment 1 に対する治療は，ほほ すでに確立されているといって問題ないと思われる，LFB を使用せざるを得なかった 1 例で皮質梗塞を生じている以 外に合併症は認めていなかった。 バイパスおよび近位内頝 動脈閉塞にて全例で良好な転帰が得られている.

Segment 2 の症例においても，バイパス術はきわめて高 い有用性を発揮する，先にも述べたが, trappingしても 血流の流出路を OpthA と PComA に求めることが可能で あり，理論上は動脈瘤の性状にかかわらず治療が可能とな るからである。しかしながら，OpthA をも巻き込むよう な症例で OpthA をどう処理するか, PComA が hypoplastic な症例で, これを流出路にしてよいのか, またその場 合には，いったい何 $\mathrm{mm}$ 以上の径があれば大丈夫なの か, 抗血小板薬でこの問題を解決できるのか, など今後に 課題が残っているのも事実である。われわれのシリーズに おいても，これらの問題に直面し合併症を生じたケースが 認められていた。

Segment 3 は，理論的にも治療法の選択が困難である． われわれの提示した 2 つの手法は，時に有効であると考え られるが,これらで対処不可能な症例に対しては, AChoA の犠牲は免れ得ない. AChoA への再建の報告も あるが ${ }^{10)}$ ，あくまでもリカバリーの手法であり，計画して 行うものではない，血豆状動脈㢚に対しては, wrap-clipping は魅力的な手法であるが8)，やはり Segment 3 で は, AChoA を避けて wrap することは困難である.

これらを考慮すると, Segment 3 の困難な動脈瘤に対し ては，新たな治療として flow diverterには大きな期待が もたれるものと考えられる。しかしながら，この手法も相 当の習熟を要するうえ, 出血抒よび血栓症など治療成績が 定まっておらず，自然歴や従来の治療法との優劣はいまだ
明らかではないことに留意が必要である13).

\section{結語}

clipping 困難な内頚動脈瘤に対して, バイパス併用手術 の治療成績は良好である。しかし，PComAょり末梢部の ものでは課題が残っている.

\section{文献}

1) Houkin $\mathrm{K}$, Kamiyama H, Kuroda S, et al: Long-term patency of radial artery graft bypass for reconstruction of the internal carotid artery. Technical note. J Neurosurg 90: 786-790, 1999

2) Ishikawa T, Mutoh T, Nakayama N, et al: Universal external carotid artery to proximal middle cerebral artery bypass with interposed radial artery graft prior to approaching ruptured blood blister-like aneurysm of the internal carotid artery. Neurol Med Chir (Tokyo) 49: 553-558, 2009

3) Ishishita Y, Tanikawa R, Noda K, et al: Universal extracranialintracranial graft bypass for large or giant internal carotid aneurysms: techniques and results in 38 consecutive patients. World Neurosurg 82: 130-139, 2014

4) Kalani MY, Ramey W, Albuquerque FC, et al: Revascularization and aneurysm surgery: techniques, indications, and outcomes in the endovascular era. Neurosurgery 74: 482-497, 2014

5）上山博康：橈骨動脈を用いたバイパス手術．脳神経外科 22 : 911-924, 1994

6) Kazumata K, Kamiyama H, Ishikawa T, et al: Impact of cervical internal carotid clamping and radial artery graft bypass on cortical arterial perfusion pressure during craniotomy. Neurosurg Rev 37: 493-499, 2014

7) Kazumata K, Nakayama N, Nakamura T, et al: Changing treatment strategy from clipping to radial artery graft bypass and parent artery sacrifice in patients with ruptured blister-like internal carotid artery aneurysms. Neurosurgery 10 (Suppl 1): 66-72, 2014

8) Kubo Y, Ogasawara K, Tomitsuka N, et al: Wrap-clipping with polytetrafluoroethylene for ruptured blisterlike aneurysms of the internal carotid artery. Technical note. J Neurosurg 105: 785-787, 2006

9) Lylyk P, Miranda C, Ceratto R, et al: Curative endovascular reconstruction of cerebral aneurysms with the pipeline embolization device: the Buenos Aires experience. Neurosurgery 64: 632-642, 2009

10）太田仲郎, 谷川緑野, 江田大武, ほか：巨大血栓化動脈瘤に 対する外科治療一安全な主幹動脈再建と穿通枝の再建. 脳卒 中の外科 43: 267-274, 2015

11) Szikora I, Berentei $Z$, Kulcsar $Z$, et al: Treatment of intracranial aneurysms by functional reconstruction of the parent artery: the Budapest experience with the pipeline embolization device. AJNR Am J Neuroradiol 31: 1139-1147, 2010

12）高橋 淳, 宮本 亨：部分血栓化巨大中大脳動脈瘤に対する 手術. No Shinkei Geka 39: 129-139, 2011

13) van Rooij WJ, Sluzewski M, van der Laak C: Flow diverters for unruptured internal carotid artery aneurysms: dangerous and not yet an alternative for conventional endovascular techniques. AJNR Am J Neuroradiol 34: 3-4, 2013 